\title{
Introduction to the Service Science Minitrack
}

\author{
Fu-ren Lin \\ Institute of Service Science \\ National Tsing Hua University \\ frlin@mx.nthu.edu.tw
}

\author{
Paul P. Maglio \\ School of Engineering \\ University of California, Merced \\ pmaglio@ucmerced.edu
}

\author{
Michael J. Shaw \\ Dept of Business Administration \\ University of Illinois, Urbana-Champaign \\ mjshaw@uiuc.edu
}

Now in its 14th year, the Service Science Minitrack at HICSS brings together researchers and practitioners working in service science, the interdisciplinary study of service that combines perspectives from science, management, engineering, and design to innovate in service and service systems. Service science has had a global impact, with hundreds of universities worldwide offering courses, programs, or degrees related to service science, and with dozens of academic research institutes and groups established. This minitrack is a platform for researchers and practitioners to share work, exchange ideas, and present results from this emerging discipline.

Service science focuses on the design, development, and managerial issues of service systems, integrated, value-creating configurations of service providers, their clients, their partners, and others. The best-performing service systems are IT-enabled, customer-centered, relationshipfocused, and knowledge-intensive, spanning multiple formal and informal organizations. Because of this multidisciplinary context, researchers and practitioners in management, social sciences, and computer science are all working to increase service innovation. These multiple perspectives can be unified using the theoretical construct of the service system, in which entities (people, businesses, government agencies, etc.) interact to co-create value via value propositions that describe dynamic reconfigurations of resources. The framework of value creation in complex service systems requiring elaboration of various stakeholder perspectives and understanding the context of use for specific cases to enable effective value creation, especially given advanced and autonomous technology - has emerged as a central unifying framework.

The increasing contributions to economic outputs from service activities means that service innovation is a major part of most business models today. Even in traditional manufacturingdriven industries, the importance of service has surpassed most other corporate competencies. From the outset, efforts in creating, composing, and delivering services call for systematic studies of managerial, technical, and social issues. Combining managerial, organizational, and technical perspectives, service science research and education aims to create T-shaped service professionals with technological, business, and social-organizational skills.

At HICSS 54 (2021), the Service Science minitrack connects disciplinary research with the interdisciplinary framework of value creation in complex service systems, focusing on the use of information technology and the effects of the digital economy on service. The minitrack received submissions of research papers from a variety of disciplines and a variety of participating communities. We note that several addressed issues related to service in the context of the COVID-19 pandemic, some relied on empirical studies, other made use of simulationbased models. Accepted papers address a variety of issues related to technologies in service, such as service system design in manufacturing settings, ethical concerns for data-driven services in the context of COVID-19, sustainable foodservice ecosystems, customer choice in digital service platforms, and the use of artificial intelligence as a service. 